Special Article

\title{
Hemovigilance in France
}

\author{
Patrick Hervé ${ }^{1,2}$ \\ Marie-Françoise L. des Floris ${ }^{2}$ \\ Danielle Rebibo ${ }^{1}$ \\ Pascal Morei ${ }^{2}$ \\ Georges Andreu ${ }^{1}$
}

\section{Introduction}

Blood transfusion safety can be defined as a series of processes implemented to either remove or reduce allogeneic blood transfusionrelated immunologic or infectious risks. Hemovigilance is an element of transfusion safety. According to the French law of $4^{\text {th }}$ January 1993: the hemovigilance system is a set of surveillance procedures from the collection of blood and its components to the follow-up of recipients aimed at collecting and assessing information on unexpected or undesirable effects resulting from the therapeutic use of labile blood products and to prevent from their occurrences.

Therefore the scope of hemovigilance encompasses all steps from donor to recipient follow-up involved in conventional transfusion and may cover cell therapy as well. However, few hemovigilance networks in the world include the donor's side, and most focus on untoward and unexpected effects of blood transfusion occurring in recipients.

Hemovigilance aims at improving links between hospitals and blood transfusion centers, through:

- a complete traceability of blood components (i.e. the capacity to identify the
In this work the organization of the hemovigilance system in France, the alert system related to un desirable transfusion effects and the search for seropositive blood donors is discussed.

Rev.bras.hematol.hemoter., 2000(22) (3): 368-373

Key words: Transfusion medicine, epidemiology

recipient for any given blood component and conversely to trace all components received by a given patient);

- transfusion incident reports (TIR), which have to be analyzed and filled by both hemovigilance actors, from the hospital and from the blood transfusion center;

- mandatory reporting at a national level of any fatality associated with blood transfusion has been introduced in United States of America since 1975;

- the concept of a European network has been launched in 1998 by Belgium, Denmark, France, Luxembourg, the Netherlands, Portugal, Spain, Switzerland, with a simple objective of being able to share any alert that could involve several recipients.

\section{The organization of hemovigilance in France}

Hemovigilance is performed to meet three objectives at both the local and national level: to identify risks and their related factor(s) and monitor these risks. The alert function cannot be dissociated from epidemiological surveillance because both processes involve evaluating the impact of the preventive measures in place. The incidence of risks must be estimated and their

1 - Etablissement Français du Sang, 100, avenue de Suffren 75015 Paris, France

2 - Etablissement Français du Sang Bourgogne Franche-Comté, 1 boulevard A. Fleming, BP 1937, 25020 Besançon cedex, France 
evolution followed up for each type of recorded transfusion-related incident.

At the blood collection level which is part of donor selection, the goal of hemovigilance is to assess the relevance of various medical indicators present in individuals who wish to donate blood. At the transfusion level, the goal of hemovigilance is to estimate the incidence of transfusion-induced side effects in recipients (e.g. viral or bacterial contamination, alloimmunization transfusion attribution errors). The incidence and prevalence of transfusionassociated incidents occasionally justifies the distinction between the three elements of the hemovigilance strategy: the alert system, recipient surveillance and blood collection surveillance $(1,4,7)$ :

1) The alert system involves recording the occurrence of adverse events, measuring their prevalence in a given population or geographic area, and studying the characteristics of such unusual events to notify relevant partners and key players (establishing transfusion-associated incident prevalence registries). Careful interpretation of the data gathered as part of the alert system is required, even in the absence of meaningful denominators, and clearly defined imputability criteria must be established.

\section{2) Epidemiological surveillance of recipients.}

It is the second important function of hemovigilance. It involves keeping records of recipients (their number and clinical status), and of transfused blood components (number and type). This surveillance strategy makes it possible to analyze and interpret data pertaining to adverse reactions, in terms of risks for recipients. Know ledge of meaningful denominators helps to interpret the available data related to such adverse reactions and to analyze tendencies both present and future. It also allows estimation of the incidence of adverse reactions depending on the nature of the transfused blood component and donor characteristics. Risk variation can be interpreted, the evolution of risks followed with time and the impact of preventive measures evaluated.
Biological surveillance of recipients also allows estimation of residual transfusion-related risks. Thus it is an integral part of hemovigilance and justifies the creation of a transfusion registry in all cases. Implementing such an activity entails considerable costs. Frequently, patients are reluctant to provide feedback or give information that is incomplete, impairing the feasibility of systematic biological surveillance for all recipients of labile products. Successful biological surveillance is only possible when patients are motivated to reduce the incidence of refusals to donate or the number of individuals lost to follow-up.

The selection of the biological tests must be made with regard to their value from an epidemiological viewpoint as well as their cost. Opinions in France still diverge as to whether reduced surveillance, restricted, to $\mathrm{HCV}$ and HBV screening, should be performed versus broader surveillance, including HIV screening. Although it is agreed that post-transfusion surveillance must include a systematic search for irregular agglutinins interest in using the ALT test remains a subject of controversy. Implementing epidemiological surveillance of recipients at national level provided that the transmission and dissemination of information are strictly controlled, helps to detect new risks that may be of an epidemic nature, which would be difficult to detect at local level (3).

The epidemiological surveillance of blood component recipients involves keeping a transfusion registry. This registry is an integral part of the medical registry and should contain all of the transfusion-related data available on patients and, when applicable, records of transfusion-induced reactions or accidents. The transfusion registry should also contain the results of immunologic and hematologic analyses, the results of pre - and sometimes post-transfusion virus detection tests, the prescription for blood components as well as any information pertaining to the transfusion procedure itself and the transfusion surveillance strategy. It should indicate the number of transfused patients and their characteristics, the number and nature of the transfused blood components, and the occurrence of immediate adverse reactions. 


\section{3) Epidemiological surveillance of blood donors}

The objectives include gaining knowledge in the various parameters leading to donor exclusion and of current trends in establishing such parameters. This includes know ledge about the prevalence of the various biological markers motivating donor exclusion, either before donation (medical selection or self-exclusion) or after donation (biological selection or secondary self-exclusion).

Such epidemiological surveillance of blood donation must consider criteria such as collection methods and location, the characteristics of blood donation volunteers, the type of blood component derived from donation as well as the reasons for donor exclusion. All these data should be recorded in a national blood collection surveillance registry.

The residual risk of viral infection can be estimated, based on the data gathered on the number and percentage of seropositive donations in previous years, the prevalence of seropositive blood donors (first-time versus repeat donors), the length of the preseroconversion window period, the sensitivity of the screening tests used, the average number of blood components prepared from one blood donation and the probability of blood products being contaminated. These models have made it possible to select a number of preventive measures. In France, it has been decided not to generalize p24 antigen screening and not to introduce a second HIV screening test in the battery of tests used for blood donors, particularly in view of the prevalence of HIV in blood donors and the current improved medical selection of blood donors.

The evaluation of blood donation safety can be based on the follow-up of recipient cohorts by evaluating residual risks in given populations, such as in multitransfused patients with thalassemia.

To be efficient, the surveillance system must identify the blood component before transfusion to the recipient, after standard codification procedures, with data provided on blood component bags, so that the donor can be identified as soon as transfusion-induced adverse reactions occur this concept is referred to as traceability (donor/blood donation/ recipient linkage). Traceability is defined by three distinct elements:

1) the nominal prescription for blood components, 2) the distribution sheet stating recipient name, 3) once completed, the return of this sheet to the transfusion center after the procedure has been completed. To be effective, traceability must be $100 \%$ successful.

Epidemiological surveillance implies the setting up and management of a serum library, or even a biolibrary (cells, serum and DNA) in which records are kept of blood component donors used as well as material from recipients. Re-implementation of a biolibrary is complex and expensive. Specifications must be drawn up on criteria such as the length of sample storage ( 5 to 20 years, depending on medicolegal and epidemiological objectives), storage temperature (liquid nitrogen), sample volume (1 to $2 \mathrm{ml}$ ), container contents (plastic straws), the electronic data management of data moving in and out, and compliance with ethical rules (e.g. informed consent, right to withdraw one's samples from the library).

Correct storage of biological samples is an essential tool for efficient epidemiological surveillance; however a biolibrary is only justified if it is part of an overall well-defined objective. As an example, in France, a measure has been implemented to exclude all previously transfused persons from donations. The collection and long-term storage of serum and DNA samples from excluded donors will make it possible to analyze them at a later time with state-of-the-art biological tools and to decide whether the reasons for their exclusion were appropriate and therefore justified.

These aspects of hemovigilance may be illustrated by concrete examples from the French hemovigilance network:

\section{Bacterial contamination}

This untoward effect of blood transfusion has been recognized since the early times of blood transfusion, and countless number of studies have been devoted to a better understanding and to 
prevent its occurrence. However, as it is a rare event, and moreover not commonly fully investigated, there was no collective awareness of its importance for decades, although convincing reports were published and well known $(2,4)$.

During the first 18 months after the implementation of hemovigilance in France, seven fatalities related to bacterial contamination of blood components were reported, while three fatalities related to $A B O$ incompatibility were reported over the same period, leading to the awareness of bacterial contamination as a major blood transfusion complication in the whole French transfusion community.

A working party was created, including transfusionists, bacteriologists and epidemiologists. This working party introduced several active measures: guidelines for investigating a suspected bacterial contamination were produced in October 1995, followed by guidelines for cutaneous asepsy procedure before donation in September 1996.

A research program was initiated, covering the following investigations:

- evaluation of bacteria detection by culture in platelet concentrates before distribution;

- assessment of phagocytosis and bactericidy in whole blood;

- evaluation of diverting out the first 30 $\mathrm{ml}$ of blood from the blood bag as a measure to reduce the incidence of initial contamination;

- development of a case-control study to identify risk factors for this transfusion complication (BACTHEM study).
Apart from the research program, intensive awareness rising on bacterial contamination was conducted within the hemovigilance network, and in blood collection staffs, with a reassessment of bacteremia risk factors in donors.

The table above indicates fatality reports in France related to bacterial contaminations.

The small number of reports makes any interpretation of these results difficult. However, it is tempting to hypothesize that the sensitization to this complication, along with many new procedures introduced by most blood transfusion centers between the end of 1995 until 1999 (including cutaneous asepsy procedures, revised donor questioning, introduction of collection bags specifically designed for diverting the first $30 \mathrm{ml}$ of collected blood, and implementation of universal leukodepletion at the blood center, with a more standardized time and temperature control between collection and processing) may have played a role in reducing the incidence of bacterial contamination in France. Long-term reporting through the hemovigilance network will provide useful information to confirm this trend.

\section{Impact of universal leukodepletion on non-hemolytic febrile transfusion reactions (NHFTR)}

A reduction of the incidence of NHFTR could be expected as a consequence of universal leukodepletion. During two 18month periods of before and after the full implementation of leukodepletion, the

\begin{tabular}{l|c|c|c|c|}
\hline & $\begin{array}{c}\text { Red cell } \\
\text { concentrates }\end{array}$ & $\begin{array}{c}\text { Pooled platelet } \\
\text { concentrates }\end{array}$ & $\begin{array}{c}\text { Apheresis } \\
\text { platelet } \\
\text { concentrates }\end{array}$ & TOTAL \\
\hline April 1994 to March 1995 & 3 & 0 & 2 & 5 \\
\hline April 1995 to March 1996 & 1 & 2 & 2 & 5 \\
\hline April 1996 to March 1997 & 3 & 0 & 0 & 3 \\
\hline April 1997 to March 1998 & 1 & 0 & 2 & 3 \\
April 1998 to March 1999 & 0 & 0 & 1 & 1 \\
\hline April 1999 to February 2000 & 0 & 0 & 1 & 1 \\
\hline
\end{tabular}


analysis of transfusion incidents reports related to red cell concentrates showed a significant decrease of this untoward event $(-41 \%$ without identified HLA antibodies, and $-55 \%$ with concomitant HLA antibodies), while other immediate side effects unexpected to be influenced by the measure were found stable (red cell antigen incompatibilities, allergic reactions, hypotension, volume overload).

\section{ABO incompatibility}

Hemovigilance provides useful information to analyze the various causes of this untoward effect of blood transfusion, to remind known preventive measures, and to propose new ones. Two hundred and twentyseven cases of immunologic accidents have been analyzed in France (6). The results show three critical factors in the occurrence of this type of incident: the relevance of the prescribed clinical examinations, the way in which the biological results are taken into account and the exchange of information between hospitals and blood transfusion center. Three types of errors have been identified:

- technical errors

- organizational errors

- human errors.

In 1998, 23 ABO immunological accidents with grade 3-4 of imputability, and 27 in 1999, have been reported from the French Agency of Sanitary Safety for Health Products.

\section{Use of post-donation counter-indication records as an indicator to prevent infectious transfusion-related incidents}

The modifications observed in donors' Health within 48 hours postdonation may be related to an infectious episode which occurred before or at the time of donation. Counter-indications to donation found postdonation have been systematically recorded in Besançon Blood Transfusion Center (5). These include medical problems notified by donors, or the discovery of abnormalities unnoticed at the time of the previous donation. A form is filled by the informed physician, which leads to discarding the blood product obtained from this donation, provided it is not too late. When the information is obtained after the blood product transfusion, the clinician who has performed the transfusion is informed.

Over the last two years, 1182 cases of counter-indications to donation were reported post-donation, representing $0.57 \%$ of the 205572 donations performed. Medical problems identified shortly post-donation accounted for $46.1 \%$ of the cases, $32.1 \%$ were revealed by abnormal blood counts. Eight hundred and sixty-one blood products derived from these 926 donations were not distributed, for the others no side effects were observed. $21.6 \%$ of the cases $(n=256)$ should have led to donor exclusion from the previous donation. Undetected risk factors included risk behavior related to 111V: 66 cases, hepatitis C: 51 and Creutzfeldt-Jakob disease: 32. Yet, no contamination has been reported to date.

\section{Conclusion}

Hemovigilance may be a useful tool not only to make the medical community aware of blood transfusion-related side, but also to assess the efficacy of a new safety measure. Its interest lies in the fact that it gives a nationwide information, which cannot be provided by a study restricted to a small number of patients in a few clinical settings.

\section{Hemovigilância na França}

Patrick Hervé, Marie-Françoise L. des Floris, Danielle Rebibo, Pascal Morei, Georges Andreu

\section{Resumo}

No relato são apresentados a spectos da organização da hemovigilância na França, o sistema de alerta relacionado com reações transfusionais indesejáveis e a busca de receptores sorologicamente positivos.

Rev.bras.hematol.hemoter.,2000(22)(3):368-373

Palavras-chave: Medicina transfusional, epidemiologia 


\section{References}

1. Debeir J. et al. The French haemovigilance network, Vox Sang 1999, 77 (2): 77-81.

2. Engelfriet $C P$, Reesink HW. Bacterial contamination of blood components. Vox Sang. 2000, 78: 59-67.

3. Hervé P. Sécurité transfusionnelle: risques émergents ou hypothétiques. Transf Clin Biol., 2000; 7:30-37.

4. Morel P, Hervé P. Surveillance of blood transfusion safety: contribution of the hemovigilance strategy in France. Transf. Med. Rev. 1998, 2:109-127.

5. Morel $P$, Leconte des Floris MF, Pouthier $F$, Devillers $M$, Hervé $P$. Prevention of infectious transfusion-related inciden ts: use of post donation counter-indication records as an indicator. Transfusion 1999, 39, suppl 10:32.

6. Rouger P, Le Pennec PY, Noizat-Pirenne F. Analyse des risques immunologiques en transfusion sanguine: période 1991-1998. Transf. Clin. Biol. 2000, 7:9-14.

7. Salmi LR, Azanowsky JM, Perez $P$ et al. Haemovigilance in France: where we stand in 1985. Proceedings of the ISBT-Ed by $U$. Rossi, A.L. Massaro, G. Sciorelli. Venezia $2^{\text {nd }}$ $5^{\text {th }}$ July 1995. Edizioni SLMTI 1997: 964-974.

Recebido: 08/06/2000

Aceito: 11/09/2000 